\title{
Robotic single-incision laparoscopic cholecystectomy
}

\author{
Philippe Morel • Francois Pugin • Pascal Bucher • \\ Nicolas C. Buchs $\cdot$ Monika E. Hagen
}

Received: 15 April 2011/Accepted: 22 August 2011/Published online: 22 October 2011

(C) The Author(s) 2011. This article is published with open access at Springerlink.com

\section{Background}

Single-port laparoscopy attempts to further reduce the surgical impact of minimally invasive surgery when compared to conventional laparoscopy [1-4]. Single-port laparoscopy might in general result in enhanced cosmetic outcomes and potentially reduced pain when compared to the conventional multi-port technique [5-8]. While manual single-port laparoscopy comes with certain technical limitations [1], a newly approved single-site platform used with the da Vinci Si Surgical System (Intuitive Surgical, Sunnyvale, CA, USA) might facilitate this technique. We present the video of our 2 nd patient undergoing this new technique.

\section{Methods}

A 44-year-old female patient with a BMI of $26.8 \mathrm{~kg} / \mathrm{m}^{2}$ and confirmed cholelithiasis underwent robotic single incision laparoscopy using novel, flexible instruments mounted to the da Vinci Si Surgical System. For the procedure, a peri-umbilical skin incision of about $2.5 \mathrm{~cm}$ was placed. An open access to the abdominal cavity was formed and a special silicon port with 4 access points was

Electronic supplementary material The online version of this article (doi:10.1007/s11701-011-0310-7) contains supplementary material, which is available to authorized users.

P. Morel $(\bowtie) \cdot$ F. Pugin $\cdot$ P. Bucher · N. C. Buchs .

M. E. Hagen

Division of Digestive Surgery, Department of Surgery,

University Hospital Geneva, 4, Rue Gabrielle-Perret-Gentil,

1211 Geneva, Switzerland

e-mail: philippe.morel@hcuge.ch installed. An 8.5-mm straight port for a camera, 2 curved 5-mm cannullae-crossing at the level of the abdominal wall-and a 5-mm straight laparoscopic trocar were introduced through this port. The robotic platform automatically switched the arm control to facilitate intuitive instrument control. Robotic single-port cholecystectomy was performed according to standard clinical practise using the flexible robotic instruments under laparoscopic retraction.

\section{Results}

This 2nd case in our experience was performed without conversions or any additional ports, taking $58 \mathrm{~min}$ at the surgical console. Docking time was $11 \mathrm{~min}$. No intra- or postoperative complications occurred. The patient was discharged $6 \mathrm{~h}$ after the procedure.

\section{Conclusions}

Robotic single-port cholecystectomy appears feasible in our early experience. Instruments and platform design seem to overcome some of the technical limitations of manual single-port laparoscopic cholecystectomy. Comparative trials are needed to confirm these potential advantages.

Conflict of interest Dr. Monika Hagen has a financial relationship with Intuitive Surgical. All other authors have nothing to disclose. Written informed consent was obtained from the patient for publication of this Case Report and any accompanying images. A copy of the written consent is available for review by the Editor-in-Chief of this journal. 
Open Access This article is distributed under the terms of the Creative Commons Attribution Noncommercial License which permits any noncommercial use, distribution, and reproduction in any medium, provided the original author(s) and source are credited.

\section{References}

1. Antoniou SA, Pointner R, Granderath FA (2011) Single-incision laparoscopic cholecystectomy: a systematic review. Surg Endosc 25:367-377

2. Bucher P, Pugin F, Ostermann S, Morel P (2010) Patient's point of view on surgical innovations: For less traumatic surgery and enhanced recovery. Innovations chirurgicales et point de vue du patient: vers une chirurgie moins traumatisante et une réhabilitation accélérée. Rev Med Suisse 6:1292-1297

3. Hagen ME, Wagner OJ, Inan I, Morel P, Fasel J, Jacobsen G, Spivack A, Thompson K, Wong B, Fischer L, Talamini M, Horgan S (2010) Robotic single-incision transabdominal and transvaginal surgery: initial experience with intersecting robotic arms. Int $\mathrm{J}$ Med Robot 6:251-255
4. Brunner W, Schirnhofer J, Waldstein-Wartenberg N, Frass R, Pimpl K, Weiss HG (2009) New: single-incision transumbilical laparoscopic surgery. Eur Surg 41:98-103

5. Canes D, Berger A, Aron M, Brandina R, Goldfarb DA, Shoskes D, Desai MM, Gill IS (2010) Laparo-endoscopic single site (LESS) versus standard laparoscopic left donor nephrectomy: matched-pair comparison. Eur Urol 57:95-101

6. Crouzet S, Haber GP, White WM, Kamoi K, Goel RK, Kaouk JH (2010) Single-port, single-operator-light endoscopic robot-assisted laparoscopic urology: pilot study in a pig model. BJU Int 105:682-685

7. Kim TJ, Lee YY, Cha HH, Kim CJ, Choi CH, Lee JW, Bae DS, Lee Jh, Kim BG (2010) Single-port-access laparoscopic-assisted vaginal hysterectomy versus conventional laparoscopic-assisted vaginal hysterectomy: a comparison of perioperative outcomes. Surg Endosc 24:2248-2252

8. Tsimoyiannis EC, Tsimogiannis KE, Pappas-Gogos G, Farantos C, Benetatos N, Mavridou P, Manataki A (2010) Different pain scores in single transumbilical incision laparoscopic cholecystectomy versus classic laparoscopic cholecystectomy: a randomized controlled trial. Surg Endosc 24:1842-1848 